\title{
Occurrence of nudicaulin structural variants in flowers of papaveraceous species
}

\author{
Evangelos C. Tatsis ${ }^{a}$, Hartmut Böhm ${ }^{\mathrm{b}}$, Bernd Schneider ${ }^{\mathrm{a}, *}$ \\ ${ }^{a}$ Max Planck Institute for Chemical Ecology, Hans-Knöll-Straße 8, Beutenberg Campus, D-07745 Jena, Germany \\ ${ }^{\mathrm{b}}$ Friedrich-Wilhelm-Murnau-Straße 20, D-14480 Potsdam, Germany
}

\section{A R T I C L E I N F O}

\section{Article history:}

Received 20 December 2012

Received in revised form 15 April 2013

Accepted 19 April 2013

Available online 14 May 2013

\section{Keywords:}

Meconopsis cambrica

Papaver alpinum

Papaver nudicaule

Anthocyanins

Flavonols

Flower pigments

Nudicaulins

HMG conjugates

Papaveraceae

\begin{abstract}
A B S T R A C T
The intense color of yellow Papaver nudicaule flowers is conferred by the presence of nudicaulins, a group of alkaloids with a unique pentacyclic skeleton composed of an indole ring and a polyphenolic moiety. Petals from eight different Papaveraceae species composed of different color varieties were probed for the presence of nudicaulins. In addition to their occurrence in yellow P. nudicaule flowers, nudicaulins I-VIII were detected and quantified in orange flowers of $P$. nudicaule, and in yellow and orange Papaver alpinum flowers. Meconopsis cambrica petals showed a divergent nudicaulin spectrum, with compounds having an attached 3-hydroxy-3-methyl-glutaryl group (HMG) instead of a malonyl unit at one of the glucose units. Flavonols and anthocyanins that accompany nudicaulins were identified. The taxonomical significance of the occurrence of nudicaulins is briefly discussed.
\end{abstract}

(c) 2013 Elsevier Ltd. All rights reserved.

\section{Introduction}

Both the shape and the color of flowers, especially of petals, play a crucial role in how plants interact with their environment, specifically, in the chemical communication between plants and their pollinators. The color of petals usually is conferred by the presence of distinct chemical structures. Two major classes of flower pigments, anthocyanins and carotenoids, are responsible for the intense colors of most plants' flowers, while pigments such as betalains and aurones are restricted to a limited number of taxonomical units (Grotewold, 2006; Tanaka et al., 2008).

Nudicaulins, an elusive group of flower pigments, generate the color of the dark yellow petals of Papaver nudicaule. They were isolated for the first time by Price et al. (1939). Early trials to elucidate their structures led to the conclusion that nudicaulins did not belong to one of the known classes of flower pigments but seemed to be a new group of nitrogen-containing compounds (Harborne, 1965). Based on nuclear magnetic resonance (NMR) spectroscopic and mass spectrometric (MS) analyses, a pentacyclic indole alkaloid skeleton, decorated with a glucose and a sophorose unit, was proposed (Schliemann et al., 2006). Additional NMR experiments and chemical modifications resulted in a revised constitution of the nudicaulin aglycon, namely 12-(4-hydroxyphenyl)-3,

\footnotetext{
* Corresponding author. Tel.: +49 3641 571600; fax: +49 3641571601.

E-mail address: schneider@ice.mpg.de (B. Schneider).
}

11-dihydrobenzofuro[2', $\left.3^{\prime}: 1\right]$ cyclopenta[1,2-b]indole-5,7,11-triol (Tatsis et al., 2013). Furthermore, the relative configuration of the two diastereomers, nudicaulin I and II, was substantiated by rotating-frame Overhauser effect spectroscopy (ROESY) and quantumchemical calculations, and the absolute configuration was assigned by comparing the results of quantum-chemical circular-dichroism (CD) calculations and experimental CD spectra. From these data, nudicaulin I was assigned as the $(3 S, 11 R)$-diastereomer and nudicaulin II as the (3R,11S)-diastereomer (Fig. 1), i.e. $\mathrm{H}-3$ and glucose $\mathrm{A}$ are oriented to the same side of the aglycon skeleton (cis conformation) in each of the diastereomers. While the constitution of the aglycon and the carbohydrate units is not subject to variation in the nudicaulins known so far, acyl units attached to the sugars are the reason for some of the structural diversity of $P$. nudicaule's typical flower pigments.

In the present study, the petals of four $P$. nudicaule color varieties, three Papaver alpinum color varieties, and six other Papaveraceae species were examined for the occurrence of nudicaulins; the structure of the nudicaulins discovered was elucidated.

\section{Results}

\subsection{Identification of compounds}

Papaveraceous plants were chosen according to taxonomical relationships, petal colors, and the availability of herbal material 


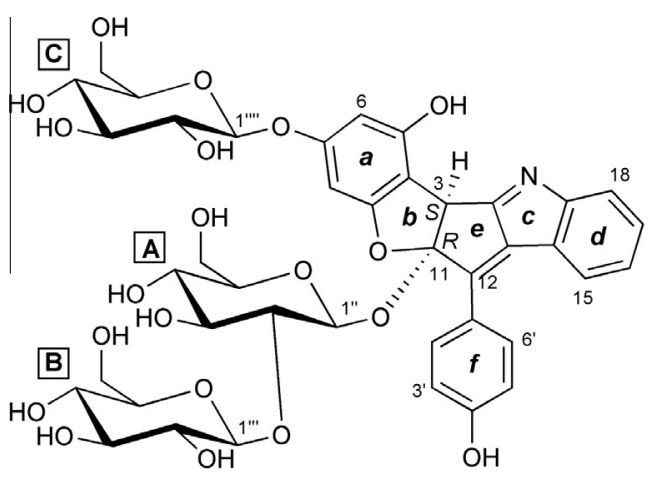

Nudicaulin I

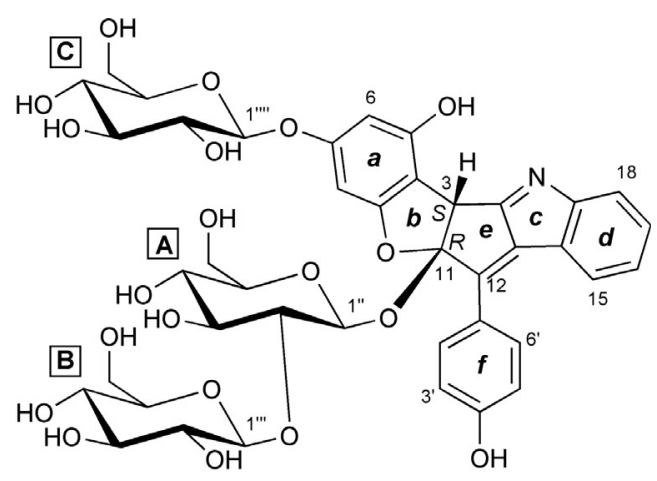

Nudicaulin II

Fig. 1. Structures of nudicaulins I and II (Tatsis et al., 2013).

or seeds. The analyzed plant species and varieties are listed in Table 1 . The flavonoids and nudicaulins found in dark yellow petals of $P$. nudicaule were investigated in detail for their structures (Schliemann et al., 2006; Tatsis et al., 2013) and the present studies of respective plant parts follow the reported methods, briefly described in the experimental section. UV/VIS, NMR and MS data confirm a previous report, in which eight nudicaulins (nudicaulin IVIII) and the eight flavonols (gossypitrin (6), kaempferol 3-O- $\beta$ sophoroside (7) and its isomer (8), kaempferol 3-O- $\beta$-sophoroside-7-O- $\beta$-glucoside (1), kaempferol 3-O- $\beta$-(sophoroside)-7-O- $\beta$ [(6-malonyl)glucoside] (4), kaempferol 3-O- $\beta$-[(6-malonyl)sophoroside]-7-O- $\beta$-glucoside (2) and kaempferol 3-O- $\beta$-[(6-malonyl)sophoroside]-7-O- $\beta$-[(6-malonyl)glucoside] (5) and its isomer (3)) were identified or partially characterized (Fig. 2; Schliemann et al., 2006). In the extract obtained from the orange petals of $P$. nudicaule, the anthocyanins pelargonidin 3-O- $\beta$-sophoroside-7-O$\beta$-glucoside (9), pelargonidin 3-O- $\beta$-[(6-malonyl)-sophoroside]-7$O$ - $\beta$-glucoside (10) and pelargonidin $3-O-\beta-[(6$-malonyl)-sophoroside]-7-O- $\beta-[(6-$ malonyl)-glucoside] (11)] were found in addition to nudicaulins I-VIII and flavonols 1-8. White petals from this species contain flavonols $\mathbf{1 - 8}$, and red petals are colored by the pelargonidin derivatives, pelargonidin $3-0$ - $\beta$-sophoroside-7-O- $\beta$ glucoside (9), pelargonidin 3-O- $\beta$-sophoroside (12) and pelargonidin 3-O- $\beta$-[(6-malonyl)-sophoroside] (13) (Fig. 2) as reported earlier (Cornuz et al., 1981). Nudicaulins were not found in white and red petals. The spectroscopic data (UV/VIS, NMR, MS) of the isolated compounds are in full agreement with the published data.

$P$. alpinum was selected for the present study because this poppy is a close relative of $P$. nudicaule within the Papaver section Meconella Spach (Carolan et al., 2006). Like $P$. nudicaule, $P$. alpinum shows yellow and orange petals but no red pigmentation. Fabergé (1943) reported the occurrence of nudicaulin and pelargonidin glycosides for P. alpinum petals. Here, these plant parts were extracted, and their metabolites isolated and analyzed according to published protocols (Schliemann et al., 2006). The HPLC, UV, LC-MS and NMR analysis of extracts from yellow petals revealed the presence of nudicaulins I-VIII and flavonols 1-8. In the extract obtained from orange petals, the anthocyanins pelargonidin $3-O-\beta$-sophoroside- $7-O-\beta$-glucoside (9), pelargonidin 3-O- $\beta-[(6-$ malonyl)-sophoroside $]-7-O-\beta$-glucoside (10) and pelargonidin 3-O- $\beta-[(6-$ malonyl $)$-sophoroside $]-7-O-\beta-[(6-$ malonyl)-glucoside] (11) were found, in addition to nudicaulins IVIII and flavonols 1-8. From the white petals of $P$. alpinum the flavonols 1-6 have been identified.

A number of other Papaver species, namely P. pilosum, P. atlanticum, $P$. aculeatum, $P$. californicum and $P$. somniferum, were selected for the present investigation in light of their different taxonomical relation to a member of the genus Meconopsis, M. cambrica (Carolan et al., 2006). However, nudicaulins were not found in the petals of all these Papaver species. Instead, the color of the petals seems to be dominated by anthocyanins (data not shown). After the lack of nudicaulins was proven unequivocally, the respective experiments were finished.

Price et al. (1939) reported the occurrence of nudicaulins in the yellow flowers of Meconopsis cambrica. This was confirmed by chromatographic comparison and UV/VIS spectroscopy with samples from P. nudicaule (Böhm, 1984, unpublished). However, the structural details of the nudicaulins in $M$. cambrica are still unknown. Investigation of flower extracts by HPLC analysis at $460 \mathrm{~nm}$, a wavelength characteristic for nudicaulins, revealed the presence of five major peaks (Fig. 3). On the basis of their UV/VIS spectra, retention times, and mass spectra, nudicaulins I, II, V and VI have been identified. No HPLC peaks at $R_{\mathrm{t}} 19.1$ and $19.3 \mathrm{~min}$ of molecular ion masses of $\mathrm{m} / \mathrm{z} 958$ were found, suggesting that the monomalonylated nudicaulins III and IV do not occur in $M$. cambrica. The same applies to dimalonylated nudicaulins VII $\left(R_{\mathrm{t}} 22.0 \mathrm{~min}, \mathrm{~m} / z\right.$ 1044) and VIII $\left(R_{\mathrm{t}} 22.6 \mathrm{~min}, \mathrm{~m} / z\right.$ 1044). Nudicaulins III and IV, where the malonyl unit is attached to 6-OH of glucose $\mathrm{A}$, and nudicaulins $\mathbf{V}$ and $\mathbf{V I}$, where the malonyl unit is attached to $6-\mathrm{OH}$ of glucose $\mathrm{C}$ (Fig. 2), were not only distinguished by their retention times (Fig. 3 ) but also the MS/MS spectra of their molecular cations (Schliemann et al., 2006).

The absorption maxima at $214,258,335$, and $458 \mathrm{~nm}$ in the UV/ VIS spectra of the HPLC peak eluted at 21.2 min suggested the presence of nudicaulin in a $M$. cambrica flower extract (Fig. 3). This chromatographic peak showed a molecular ion mass of $m / z 1016$ and mass fragments at $m / z 854,692$, and 386. The cation of $m / z$ 386 corresponds to the mass of nudicaulin aglycon, while the cations with masses of $m / z 854$ and 692 indicate the loss of one and two glucose units from the molecular cation of $m / z 1016$, respectively. The MS data point to the presence of a nudicaulin derivative, probably one with the same glucosidic moiety as nudicaulins IVIII. Given the difference of molecular mass ion $\mathrm{m} / \mathrm{z} 1016$ with the molecular ion of non-acylated nudicaulins I and II $\mathrm{m} / z \mathbf{8 7 2}$, and taking into account the fact that water is eliminated during esterification, the conjugation of an acyl unit with the elemental composition $\mathrm{C}_{6} \mathrm{H}_{9} \mathrm{O}_{4}$ was concluded to have taken place. The fraction eluted at $R_{\mathrm{t}} 21.2$ was further separated by preparative HPLC and measured by NMR. The ${ }^{1} \mathrm{H}$ NMR spectrum shows two sets of analogous signals with minor chemical shift differences between them, suggesting the presence of two co-eluting compounds, namely IX and $\mathbf{X}$, of the nudicaulin type. In the aglycon parts of the nudicaulin molecules, the only major chemical shift difference was observed for the signals of the protons $(\mathrm{H}-3)$ attached to the chiral center at C-3, appearing at $\delta 5.80$ and 5.63. Similar chemical shift differences have been observed for diastereomeric pairs of nudicaulins (Schliemann et al., 2006; Tatsis et al., 2013). Therefore it was concluded that compounds $\mathbf{I X}$ and $\mathbf{X}$ are diastereomeric counterparts. Since the concentrations of the two co-eluted 
Table 1

Occurrence and concentration of nudicaulins in petals of Papaveraceae species.

\begin{tabular}{|c|c|c|c|c|}
\hline \multirow[t]{2}{*}{ Species/variety } & \multirow[t]{2}{*}{ Flower color } & \multirow[t]{2}{*}{ Occurrence of nudicaulins } & \multirow{2}{*}{$\frac{\text { Nudicaulin I }}{\text { \% of DW1 }}$} & \multirow{2}{*}{$\begin{array}{l}\text { Nudicaulin II } \\
\% \text { of } \mathrm{DW}^{\mathrm{a}}\end{array}$} \\
\hline & & & & \\
\hline \multirow[t]{4}{*}{ P. nudicaule } & Yellow & I-VIII & 1.48 & 1.17 \\
\hline & Red & nd & & \\
\hline & White & nd & & \\
\hline & Orange & I-VIII & 1.12 & 0.83 \\
\hline \multirow[t]{3}{*}{ P. alpinum } & Yellow & I-VIII & 1.02 & 0.78 \\
\hline & White & nd & & \\
\hline & Orange & I-VIII & 0.71 & 0.65 \\
\hline P. pilosum & Pink & nd & & \\
\hline P. atlanticum & Violet & nd & & \\
\hline P. aculeatum & Orange & nd & & \\
\hline P. californicum & Orange & nd & & \\
\hline P. somniferum nigrum & Purple & nd & & \\
\hline P. somniferum album & White & nd & & \\
\hline M. cambrica & Yellow & I, II, V, VI, IX, X & 1.44 & 1.17 \\
\hline
\end{tabular}

a The crude extracts containing mixtures of non-acylated and acylated nudicaulins were subject to basic hydrolysis to afford a total amount of the non-acylated nudicaulins

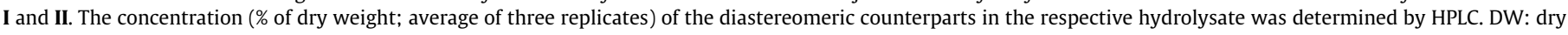
weight. nd: Not detectable.

diastereomers are not in a one-to-one ratio, the different intensities of the NMR signals were used to distinguish the signals of the two compounds.

The assignment strategy reported by Schliemann et al. (2006) and Tatsis et al. (2013) was applied to the ${ }^{1} \mathrm{H}$ NMR and 2D correlation data $\left({ }^{1} \mathrm{H}-{ }^{1} \mathrm{H}\right.$ COSY, TOCSY, HSQC and HMBC) of the mixture of the diastereomers IX and X. Briefly, the ${ }^{1} \mathrm{H}$ NMR, ${ }^{1} \mathrm{H}-{ }^{1} \mathrm{H}$ COSY and HSQC spectra show the characteristic signals belonging to each of the two aglycons: the AX system of two doublets of H-6 and H-8 (ring a), the four-spin system of $\mathrm{H}-15-\mathrm{H}-18$ of the 1.2-disubstituted ring $\mathbf{d}$ of the indole moiety, the $A A^{\prime} X X^{\prime}$ system of $\mathrm{H}-2^{\prime} / 6^{\prime}$ and $\mathrm{H}-3^{\prime} / 5^{\prime}$ from the 1,4-substituted ring $\mathbf{f}$. In addition, singlets of $\mathrm{H}-3$ were observed, which proved to be critical for establishing the connections between the substructures by means of HMBC correlations. The strong cross-signal in the ROESY spectrum (Fig. S3) between $\mathrm{H}-15$ and $\mathrm{H}-2^{\prime} / 6^{\prime}$ substantiated the $\left[2^{\prime}, 3^{\prime}: 1\right]$-annelation of the indole moiety to the central cyclopentene ring $\mathbf{e}$. According to our results and the previous findings of Tatsis et al. (2013), the spectroscopic data are in agreement with the nudicaulin aglycon structure as 12-(4hydroxyphenyl)-3,11-dihydrobenzofuro[ $\left.2^{\prime}, 3^{\prime}: 1\right]$ cyclopenta[1,2-b] indole-5,7,11-triol.

The attachment of carbohydrate units were established by HMBC correlations of protons at the anomeric centers of glucose C with C-7 and of glucose A with C-11. The HMBC cross-signal between the proton at the anomeric center of glucose B with C-2" of glucose $A$ indicated the interglucosidic bond between the two glucose units of the sophorose. The deshielded methylene carbons C-6"' $\left(\delta\right.$ 64.3 and 64.1) and H-6"' ${ }^{\prime \prime \prime} \mathrm{A} / \mathrm{B}(\delta$ 4.44/4.42; $\delta 4.22 / 4.20)$ (Table 2) suggested acyl substitution at this hydroxymethylene group of IX and X. An HSQC cross-signal at $\delta_{\mathrm{H}} 1.21 / \delta_{\mathrm{C}} 27.8$ was assignable to a methyl group of IX and one at $\delta_{\mathrm{H}} 1.28 / \delta_{\mathrm{C}} 27.7 \mathrm{~s}$ was assigned to a methyl group of $\mathbf{X}$ (Fig. S1). The methyl group signals are inconsistent with any known nudicaulin structural features and, therefore, must be attributed to the $C_{6}$ acyl unit. Each of the methyl signals displayed HMBC cross-peaks (Fig. S2) with the signal of an oxygenated carbon atom $(\delta 70.8 / \delta 70.8)$ and two methylenes (IX: $\delta 46.4,45.6$; IX: $\delta 46.4,45.8)$. In turn, the methylene protons of IX $(\delta 2.53 / 2.48 ; \delta 2.64 / 2.57)$ and $\mathbf{X}(\delta 2.62 / 2.57 ; \delta$ $2.72 / 2.66)$ correlated with the corresponding methyl groups. HMBC correlations through two bonds between the two methylene ${ }^{1} \mathrm{H}$ NMR signals of the acyl units of each diastereomer and a carbonyl carbon signal $($ IX: $\delta 2.53 / 2.48 \rightarrow \delta 172.4 ; \delta 2.64 / 2.57 \rightarrow \delta$ $174.9 ; \mathbf{X}: \delta 2.62 / 2.57 \rightarrow \delta 172.3 ; \delta 2.72 / 2.66 \rightarrow 175.0)$ and the oxygenated carbon atom ( $\delta 70.8 / 70.8)$ (Fig. S2) were observed.
These MS and NMR results allowed the acyl-type substituent to be identified as a 3-hydroxy-3-methyl-glutaryl (HMG) group. The attachment of the HMG part to the hydroxymethylene group of glucose $C$ was confirmed by the correlation peak in the HMBC spectrum (Fig. S2), between $\mathrm{H}-6^{\prime \prime \prime \prime} \mathrm{A} / \mathrm{B}$ ( $\left.\delta 4.44 / 4.42 ; \delta 4.22 / 4.20\right)$, and the carbonyl ester carbon of the HMG unit at $\delta 172.3 / 172.4$. The HMG as an acyl group attached to Glc-6-OH is common for the lignan macromolecule in Linum seeds (Struijs et al., 2008), for example, and has been also reported in petal constituents (Morikawa et al., 2009). In light of these data, nudicaulins IX and $\mathbf{X}$ were identified as isomeric 12-(4-hydroxyphenyl)-3,11-dihydrobenzofuro[2',3':1]cyclopenta[1,2- $b]$ indole-5-hydroxy-7-O- $\beta$-[6-(3-hydroxy-3-methyl-glutaryl)glucoside]-11-O- $\beta$-sophoroside.

In the ROESY spectrum (Fig. S3), cross-signals between $\mathrm{H}-3$ and $\mathrm{H}-1^{\prime \prime}$ of glucose A were observed for both nudicaulin IX and $\mathbf{X}$, indicating cis-configuration, i.e. $\mathrm{C}(3)-\mathrm{H}$ and $\mathrm{C}(11)-\mathrm{O}-\mathrm{GlcA}$ are oriented to the same side of the aglycon skeleton in each of the diastereomers, as recently reported for nudicaulin I and II (Tatsis et al., 2013). Moreover, using the integral intensity of the ROESY crosssignals between $\mathrm{H}-2^{\prime} / 6^{\prime}$ and $\mathrm{H}-3^{\prime} / 5^{\prime}$ as references (100\%), the integral intensity of the $\mathrm{H}-3-\mathrm{H}-1^{\prime \prime}$ cross-signal of nudicaulin IX was $55 \%$ and that of nudicaulin $\mathbf{X}$ was $17 \%$. Different intensities of the $\mathrm{H}-3-\mathrm{H}-\mathrm{1}^{\prime \prime}$ ROESY cross-signals were also observed for the diastereomeric pair nudicaulin I and II (Tatsis et al., 2013). From this analogy and with similar NMR data from nudicaulin IX and $\mathbf{X}$ and from nudicaulin I and II, the absolute configuration for nudicaulin IX seemed to be $(3 S, 11 R)$ and that for nudicaulin $\mathbf{X}(3 R, 11 S)$. This suggestion was confirmed by the deacylation of a crude nudicaulin mixture, resulting in nudicaulin I and II with known absolute configuration (Tatsis et al., 2013).

The only well-resolved signals between the two diastereomers nudicaulin IX and $\mathbf{X}$ were the signals of methyl groups from the HMG moiety, the signals of $\mathrm{H}-2^{\prime} / 6^{\prime}$ and the signals of $\mathrm{H}-3$. The integration of those signals (Fig. S4) revealed a ratio of $1.2: 1$ in each case between nudicaulin $\mathbf{I X}$ and nudicaulin $\mathbf{X}$, indicating that the two diastereomers are present in a scalemic mixture.

\subsection{Quantification of nudicaulins}

Eight of ten nudicaulins, which have been identified in flowers of Papaveraceae, exist in the form of acylated glucosides. In order to compare total nudicaulin concentrations of the studied species and varieties, the acyl units were removed by basic hydrolysis. As a result of hydrolysis, the compound pattern was simplified to 

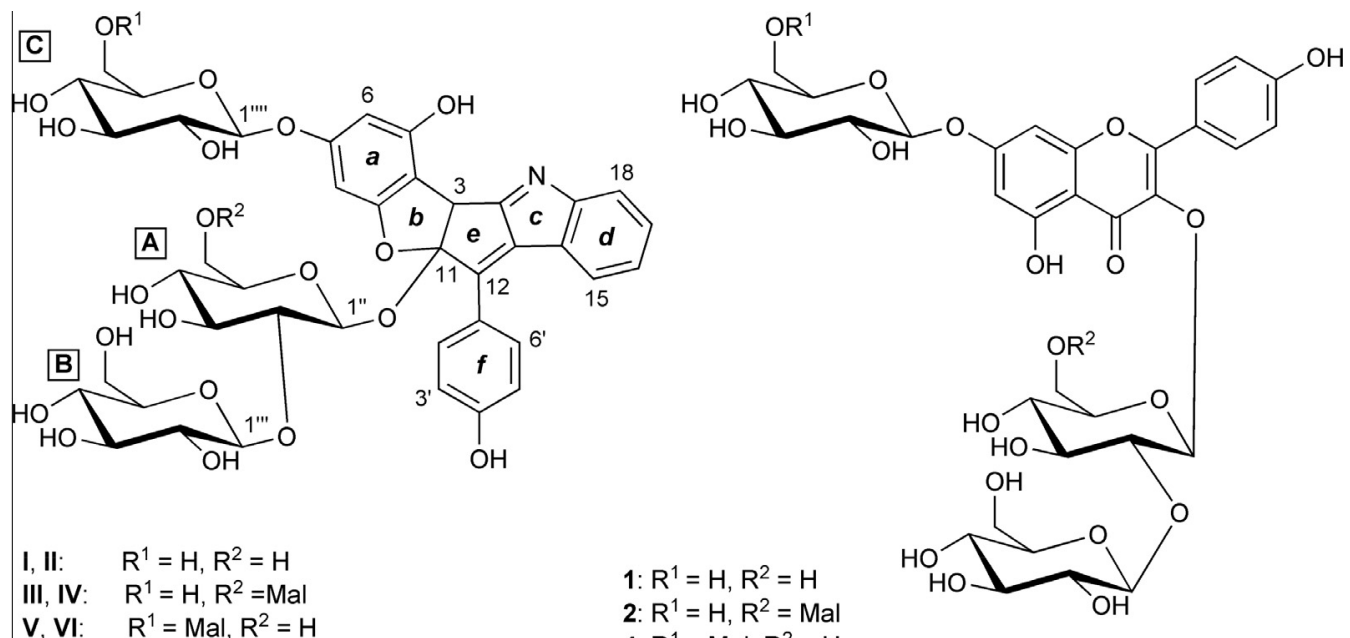

$$
\begin{array}{ll}
\text { I, II: } & \mathrm{R}^{1}=H, R^{2}=H \\
\text { III, IV: } & \mathrm{R}^{1}=H, R^{2}=\text { Mal } \\
\text { V, VI: } & R^{1}=\text { Mal, } R^{2}=H \\
\text { VII, VIII: } & R^{1}=\text { Mal, } R^{2}=\text { Mal } \\
\text { IX, X: } & R^{1}=H M G, R^{2}=H
\end{array}
$$$$
\text { 2: } \mathrm{R}^{1}=\mathrm{H}, \mathrm{R}^{2}=\mathrm{Ma}
$$$$
\text { 4: } R^{1}=M a l, R^{2}=H
$$$$
\text { 5: } R^{1}=M a l, R^{2}=M a l
$$

HMG:<smiles>CCC(=O)CC(C)(O)CC(=O)O</smiles><smiles>CCCCC(=O)O</smiles><smiles>O=c1c(O)c(-c2ccc(O)c(O)c2)oc2c(O)c(OC3OC4OC3C(O)C(O)C(O)C4O)cc(O)c12</smiles><smiles>O=c1c(OCC(O)[C@H](O)CO)c(-c2ccc(O)cc2)oc2cc(O)cc(O)c12</smiles>

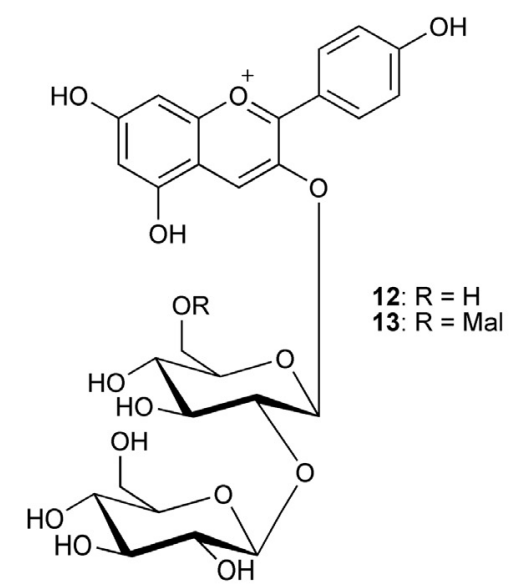

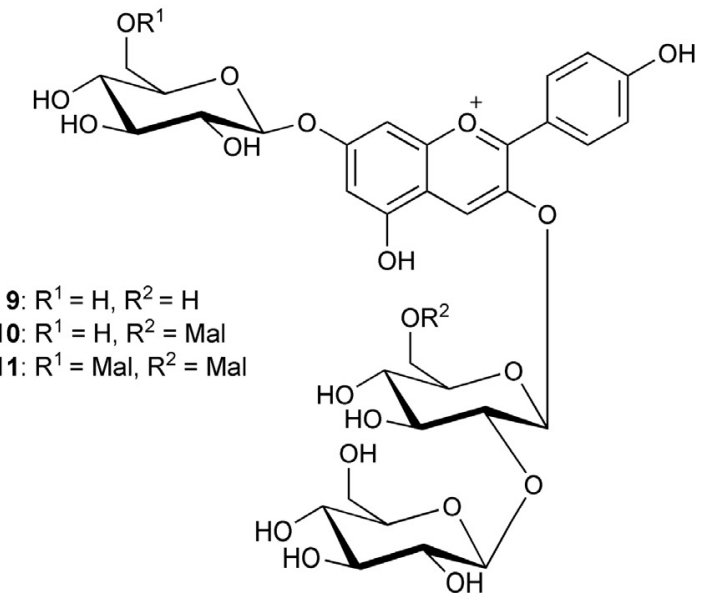

Fig. 2. Structures of the major pigments of petals from P. nudicaule, P. alpinum and M. cambrica, respectively. I-X: nudicaulins; 1, 2, 4-7: flavonols, $\mathbf{3}$ and $\mathbf{8}$ (not shown) are isomers of 5 and 7; 9-13: anthocyanins.

the nudicaulin diastereomers I and II. A sample of nudicaulin I was used as a reference standard to establish a calibration curve (Fig. S5); this curve was used to quantify nudicaulins in petal extracts by HPLC at $460 \mathrm{~nm}$. The results (Table 1 ) showed that the concentration of nudicaulins in the yellow flowers of $P$. nudicaule almost equals the concentration of nudicaulins in $M$. cambrica. It can also be seen that the concentration in the petals of $P$. nudicaule is higher than that in the petals of $P$. alpinum. In both $P$. nudicaule and $P$. alpinum, the nudicaulin content is lower in orange flowers than in yellow ones. Interestingly, in all the extracts, the concen- tration of nudicaulin I is higher than that of its diastereomer, nudicaulin II.

\section{Discussion}

The species investigated here belong to different taxonomical units, and their habitats are scattered over the world. As mentioned above, $P$. nudicaule (Iceland poppy) and P. alpinum (alpine poppy) are members of the section Meconella that is distributed 


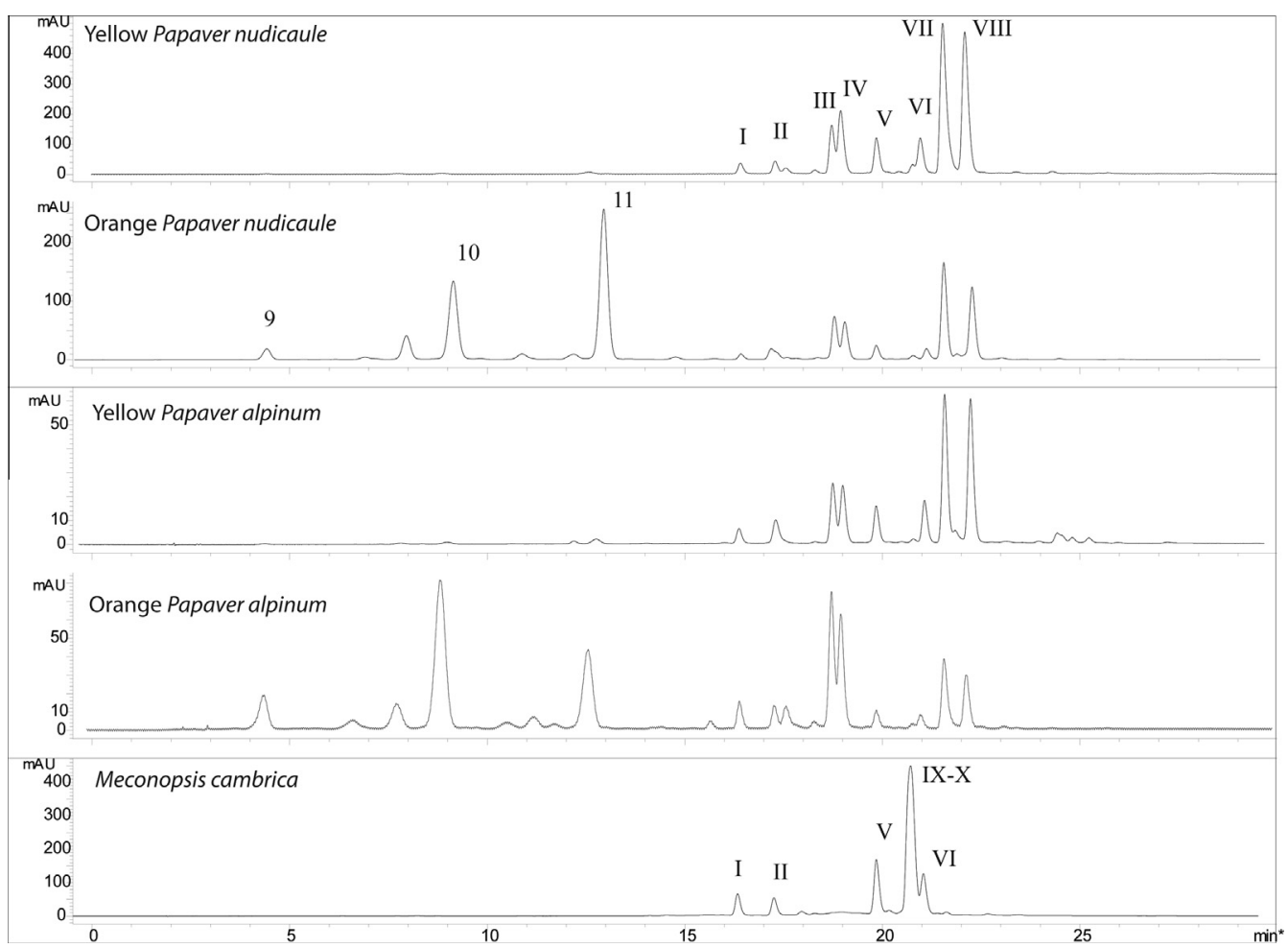

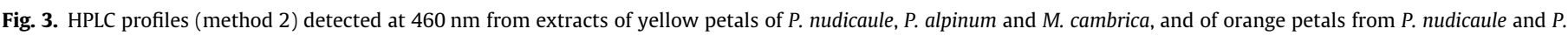
alpinum. Peak labels correspond to the numbers assigned to compounds in Fig. 2.

in arctic-alpine areas (Carolan et al., 2006). Both species share many characteristics and, notably in wild populations, appear in dimorphic populations of white and yellow flowers (Elven et al., 2009), while garden varieties include orange flowering plants. In the case of $P$. nudicaule, genotypes with red petals are also known to occur (Table 1). Wind et al. (1998) studied the flower color dimorphism of Papaver radicatum, another arctic-alpine poppy, in its habitat. An altitude-dependent gradient was observed, according to which yellow flowers were more common in high altitudes while white flowering plants were more common in lower levels, close to the sea.

Papaver californicum, representing its own section (Kadereit, 1997), and Papaver aculeatum, a member of the section Horrida Elkan, may be similar to each other. The first species is indigenous to western North America, the second to South Africa. In contrast, $\mathrm{Pa}$ paver pilosum, section Pilosa Prantl, and Papaver atlanticum, section Pseudopilosa M. Popov ex Günther, in southwestern Asia and North Africa, respectively, occur within areas typical of the genus Papaver. The opium poppy, Papaver somniferum, section Papaver L., is widespread as a crop plant (Kadereit, 1997; Carolan et al., 2006). Apart from $P$. somniferum var. album, the five species mentioned in this paragraph have orange or reddish petals (Table 1). In principle these characteristics do not exclude the presence of nudicaulins that is apparent in orange flowering $P$. nudicaule and $P$. alpinum plants.

M. cambrica (Welsh poppy) is the only European representative of a relatively large genus in the family of Papaveraceae that is also distributed in the Himalayans (Valtuena et al., 2012). Whereas this species has yellow flowers, other members of the genus have blue petals that are colored by anthocyanins and flavonols (Tanaka et al., 2001).

Often the color intensity (absorption) of flowers is enhanced by intermolecular co-pigmentation, e.g. different flavonoids (Goto and Kondo, 1991; Ono et al., 2010). However, the intense yellow color in flowers of $P$. nudicaule is conferred solely by the presence of nudicaulins. The white color results from the absence of these compounds despite the presence of flavonols. The pelargonidin derivatives are responsible for red petals and the orange color is based on the co-occurrence of anthocyanins and nudicaulins. We conclude that the pigmentome of $P$. nudicaule flowers is directly associated with the optical outcome. Corresponding considerations apply to the findings with $P$. alpinum petals. In the petals of $M$. cambrica, no significant amount of other pigments accompanied the nudicaulins. These characteristic compounds were localized only in the petals of the respective species and were not found in green and underground parts of the plants.

The clear result, namely that nudicaulins occur in Meconella species and in $\mathrm{M}$. cambrica but are lacking in all other examined $\mathrm{Pa}$ paver species of different sections, may indicate nudicaulin-containing species are outsiders within their genera. However, the conclusion does not suggest that $M$. cambrica has a close relationship to $P$. somniferum, $P$. pilosum and $P$. atlanticum as postulated by Carolan et al. (2006). The significance of nudicaulins for the position of M. cambrica in its genus (Kadereit et al., 2011) and to the relation between the section Meconella and the Asian Meconopsis would be established by the analysis of petals from yellow flowering Himalayan species.

As the nudicaulins from $M$. cambrica confirm, these compounds occur as diastereomeric pairs. The nudicaulin spectrum of the $\mathrm{Pa}$ paver species differs from that of $M$. cambrica by the absence of nudicaulins III and IV as well as of VII and VIII. However, the pair IX and $\mathbf{X}$ occurs; this pair is monoacylated with HMG in the same position where the malonyl unit is attached in nudicaulins $\mathbf{V}$ and VI (Fig. 2). Diacylated nudicaulins are obviously not synthesized in $M$. cambrica.

The quantification of nudicaulins I and II, which represent the simplest diasteromeric pair, and of the new nudicaulins IX and $\mathbf{X}$ from $M$. cambrica, shows that the $(3 S, 11 R)$-diastereomer and the $(3 R, 11 S)$-diastereomer are present in a ratio different from 1:1. The unbalanced proportion of approximately 1.2:1 suggests the 
Table 2

${ }^{1} \mathrm{H}$ and ${ }^{13} \mathrm{C}$ NMR spectroscopic data (500 MHz for ${ }^{1} \mathrm{H}$; $125 \mathrm{MHz}$ for ${ }^{13} \mathrm{C} ; \mathrm{CD}_{3} \mathrm{OD}$ ) of nudicaulins IX and $\mathbf{X}$. $^{\text {a }}$

\begin{tabular}{|c|c|c|c|c|}
\hline \multirow[t]{3}{*}{ No } & \multicolumn{2}{|l|}{ Nudicaulin $\mathbf{I X}^{\mathrm{b}}$} & \multicolumn{2}{|l|}{ Nudicaulin $\mathbf{X}^{\mathrm{b}}$} \\
\hline & ${ }^{1} \mathrm{H}$ & ${ }^{13} \mathrm{C}$ & ${ }^{1} \mathrm{H}$ & ${ }^{13} \mathrm{C}$ \\
\hline & $\delta$, mult., $J(\mathrm{~Hz})$ & $\delta$ & $\delta$, mult., $J(\mathrm{~Hz})$ & $\delta$ \\
\hline \multicolumn{5}{|c|}{ Aglycon } \\
\hline 2 & & 177.9 & & 178.0 \\
\hline 3 & $5.63, s$ & 49.6 & $5.80, s$ & 49.8 \\
\hline 4 & & 102.3 & & 102.3 \\
\hline 5 & & 156.4 & & 156.5 \\
\hline 6 & $6.31, d, 1.8$ & 99.4 & $6.31, d, 1.8$ & 99.8 \\
\hline 7 & & 162.4 & & 162.6 \\
\hline 8 & $6.25, d, 1.8$ & 92.2 & $6.25, d, 1.8$ & 92.9 \\
\hline 9 & & 161.2 & & 161.5 \\
\hline 11 & & 126.0 & & 125.7 \\
\hline 12 & & 169.7 & & 169.7 \\
\hline 13 & & 131.6 & & 131.6 \\
\hline 14 & & 122.9 & & 123.2 \\
\hline 15 & $8.31, d 7.8$ & 125.7 & $8.31, d, 7.8$ & 125.7 \\
\hline 16 & $7.57, d d, 7.8,7.8$ & 128.6 & $7.57, d d, 7.8,7.8$ & 128.6 \\
\hline 17 & $7.64, d d, 7.8,7.8$ & 131.5 & $7.64, d d, 7.8,7.8$ & 131.5 \\
\hline 18 & $7.71, d, 7.8$ & 117.4 & $7.71, d, 7.8$ & 117.4 \\
\hline 19 & & 148.8 & & 148.9 \\
\hline $1^{\prime}$ & & 123.1 & & 123.1 \\
\hline $2^{\prime} / 6^{\prime}$ & $8.62, d, 9.0$ & 139.4 & $8.57, d, 9.0$ & 139.6 \\
\hline $3^{\prime} / 5^{\prime}$ & $7.14, d, 9.0$ & 118.4 & $7.14, d, 9.0$ & 118.4 \\
\hline $4^{\prime}$ & & 168.1 & & 168.3 \\
\hline \multicolumn{5}{|c|}{ Glucose $A^{\mathrm{c}}$} \\
\hline $1^{\prime \prime}$ & $4.80, d, 7.1$ & 99.7 & $5.09, d, 7.9$ & 97.6 \\
\hline $2^{\prime \prime}$ & 3.57 & 83.8 & 3.83 & 78.2 \\
\hline $3^{\prime \prime}$ & 3.55 & 77.5 & 3.67 & 78.9 \\
\hline $4^{\prime \prime}$ & 3.05 & 71.6 & 3.37 & 70.5 \\
\hline $5^{\prime \prime}$ & 3.24 & 75.9 & 3.39 & 77.7 \\
\hline $6^{\prime \prime} \mathrm{A}$ & 3.80 & 62.1 & 3.68 & 61.7 \\
\hline $6^{\prime \prime} B$ & 3.72 & & 3.63 & \\
\hline \multicolumn{5}{|c|}{ Glucose $B^{\mathrm{C}}$} \\
\hline $1^{\prime \prime \prime}$ & $4.51, d, 7.7$ & 106.3 & $4.95, d, 7.8$ & 103.3 \\
\hline $2^{\prime \prime \prime}$ & 3.26 & 77.5 & $\approx 3.4$ & 77.9 \\
\hline $3^{\prime \prime \prime}$ & 3.08 & 78.3 & $\approx 3.2$ & $\approx 72$ \\
\hline $4^{\prime \prime \prime}$ & 3.03 & 71.6 & $\approx 3.3$ & $\approx 74$ \\
\hline $5^{\prime \prime \prime}$ & $\approx 3.3$ & 77.8 & $\approx 3.3$ & $\approx 78$ \\
\hline $6^{\prime \prime \prime} \mathrm{A}$ & 3.31 & 62.7 & 3.70 & 63.1 \\
\hline $6^{\prime \prime \prime} \mathrm{B}$ & 3.00 & & 3.24 & \\
\hline \multicolumn{5}{|c|}{ Glucose $C^{c}$} \\
\hline $1^{\prime \prime \prime \prime}$ & $4.80, d, 7.0$ & 102.1 & $4.82, d, 7.0$ & 102.3 \\
\hline $2^{\prime \prime \prime \prime}$ & 3.37 & 77.1 & 3.39 & 74.4 \\
\hline $3^{\prime \prime \prime \prime}$ & $\approx 3.3$ & $\approx 78$ & $\approx 3.2$ & $\approx 71$ \\
\hline $4^{\prime \prime \prime \prime}$ & 3.40 & $\approx 74$ & 3.40 & $\approx 74$ \\
\hline $5^{\prime \prime \prime \prime}$ & 3.59 & 75.1 & 3.59 & 75.3 \\
\hline $6^{\prime \prime \prime \prime} \mathrm{A}$ & $4.44, d d, 12.0,2.1$ & 64.1 & $4.42, d d, 12.0,2.1$ & 64.3 \\
\hline $6^{\prime \prime \prime \prime} \mathrm{B}$ & $4.22, d d, 12.1,5.8$ & & $4.20, d d, 12.0,5.4$ & \\
\hline \multicolumn{5}{|c|}{ 3-Hydroxy-3-methyl-glutaryl } \\
\hline $1^{\prime \prime \prime \prime \prime \prime}$ & & 172.4 & & 172.3 \\
\hline $2^{\prime \prime \prime \prime \prime} \mathrm{A}$ & $2.53, d, 15.3$ & 46.4 & $2.62, d, 15.3$ & 46.4 \\
\hline $2^{\prime \prime \prime \prime \prime} \mathrm{B}$ & $2.48, d, 15.3$ & & $2.57, d, 15.3$ & \\
\hline $3^{\prime \prime \prime \prime \prime \prime}$ & & 70.8 & & 70.8 \\
\hline $\mathrm{CH}_{3}{ }^{\mathrm{a}}$ & $1.21, s$ & 27.8 & $1.28, s$ & 27.7 \\
\hline $4^{\prime \prime \prime \prime \prime} \mathrm{A}$ & $2.64, d, 14.5$ & 45.6 & $2.72, d, 14.5$ & 45.8 \\
\hline $4^{\prime \prime \prime \prime \prime} \mathrm{B}$ & $2.57, d, 14.5$ & & $2.66, d, 14.5$ & \\
\hline $5^{\prime \prime \prime \prime \prime}$ & & 174.9 & & 175.0 \\
\hline
\end{tabular}

a Some chemical shifts were obtained from 2D NMR spectra (COSY, TOCSY, HSQC, HMBC).

b Chemical shifts were obtained from a mixture of nudicaulins IX and $\mathbf{X}$ and may be interchanged between the two diastereomers.

C ${ }^{1} \mathrm{H}$ NMR signals of $\mathrm{H}-2-\mathrm{H}-5$ of glucose A, glucose B and glucose $\mathrm{C}$ partly overlap. Coupling constants were not determined.

preferred formation of the energetically favored (3S,11R)-diastereomer. The presence of scalemic mixtures of diastereomers in nature has been reported (Finefield et al., 2012). The occurrence of diastereomeric nudicaulins suggests it will be fruitful to investigate the mechanism underlying their formation in plant tissue.

\section{Experimental}

\subsection{General experimental procedures}

Preparative HPLC (method 1) was performed on a Merck-Hitachi LiChrograph chromatography system (L-6200A gradient pump, L-4250 UV/Vis detector) using a Purospher STAR RP18ec column $(5 \mu \mathrm{m}, 250 \times 10 \mathrm{~mm})$ and a linear gradient $\mathrm{MeOH}-\mathrm{H}_{2} \mathrm{O}$ (0.1\% trifluoroacetic acid (TFA)) from $20 \%$ to $50 \% \mathrm{MeCN}$ in 30 min (flow rate $3.5 \mathrm{ml} \mathrm{min}^{-1}$; UV detection $254 \mathrm{~nm}$ ). Analytical HPLC was performed on an Agilent series HP1100 (binary pump G1312A; auto sampler G1313A; diode array detector G1315B, 200-700 nm) using a Purospher STAR RP18ec column $(5 \mu \mathrm{m}$, $250 \times 4 \mathrm{~mm}$; injection volume $10-25 \mu \mathrm{l}$ ). The following solvent and gradient systems were used: method 2 : solvent $A, 1 \%$ aq. TFA; solvent B, $1 \%$ TFA in MeCN, linear gradient from $10 \%$ B to $25 \% \mathrm{~B}$ in $25 \mathrm{~min}$ and isocratic for $5 \mathrm{~min}$, flow rate $1 \mathrm{ml} \mathrm{min}^{-1}$. The compounds were detected at 350 and $460 \mathrm{~nm}$.

The LC-DAD-SPE-NMR system consisted of an Agilent 1100 chromatography system (quaternary solvent delivery pump G1311A, autosampler G1313A; Agilent Technologies, Waldbronn, Germany), a J\&M photodiode array detector (DAD, detection 200-700 nm; J\&M Analytik AG, Aalen, Germany), a Spark Prospekt 2 solid-phase extraction (SPE) device (Spark Holland, Emmen, The Netherlands), and a Bruker Avance 500 NMR spectrometer (Bruker, Karlsruhe, Germany) equipped with a TCI CryoProbe ( $5 \mathrm{~mm}$ ) and a CryoFIT $^{\mathrm{TM}}$ insert (cell volume $30 \mathrm{ml}$ ). The chromatographic separation was carried out by the use of method 2. A make-up pump (Knauer, Berlin, Germany) was used to add water $\left(2.5 \mathrm{ml} \mathrm{min}{ }^{-1}\right)$ to the eluent after HPLC in order to reduce the eluotropic capacity. Every LC peak was cumulatively trapped three times on HySphere resin GP cartridges $(10 \times 2 \mathrm{~mm}, 10 \mu \mathrm{m})$ (Spark). After the cartridges were dried with nitrogen gas, the analytes were eluted with $\mathrm{CD}_{3} \mathrm{CN}$ or $\mathrm{CD}_{3} \mathrm{OD}$ and transferred through a capillary to the NMR flow cell. NMR operating frequencies were $500.13 \mathrm{MHz}$ for ${ }^{1} \mathrm{H}$ and $125.75 \mathrm{MHz}$ for ${ }^{13} \mathrm{C}$. The LC-DAD-SPE-NMR system was controlled by Bruker software HyStar 3.2, and the NMR data were acquired and processed using Topspin 2.1 . The residual ${ }^{1} \mathrm{H}$ and ${ }^{13} \mathrm{C}$ NMR signals of solvents were used as an internal standard ( $\delta$ 3.30 for ${ }^{1} \mathrm{H}$ and $\delta 48.97$ for ${ }^{13} \mathrm{C}$ in $\mathrm{CD}_{3} \mathrm{OD} ; \delta 2.00$ for ${ }^{1} \mathrm{H}$ in $\mathrm{CD}_{3} \mathrm{CN}$ ).

NMR spectra $\left({ }^{1} \mathrm{H}\right.$ NMR, ${ }^{13} \mathrm{C}$ NMR, ${ }^{1} \mathrm{H}^{1}{ }^{1} \mathrm{H}$ COSY, TOCSY, HSQC, HMBC) of isolated nudicaulins were acquired in $5 \mathrm{~mm}$ or $2.5 \mathrm{~mm}$ tubes using the Bruker Avance NMR spectrometer and a TCI cryoprobe $(5 \mathrm{~mm})$ as described above but without the CryoFITTM insert. HSQC experiments were acquired with a spectral width of $6009 \mathrm{~Hz}$ in the $F_{2}\left({ }^{1} \mathrm{H}\right)$ dimension and 22638 in the $F_{1}\left({ }^{13} \mathrm{C}\right)$ and with an acquisition time of $0.09 \mathrm{~s}$. The relaxation delay was $2 \mathrm{~s}$, the data collection matrix was $1024 \times 256$, the $t_{1}$ dimension was zero-filled to $1 \mathrm{k}$ real data points, and a $\pi / 2$ square sine bell window was applied in both dimensions. HMBC experiments were acquired with a spectral width of $6009 \mathrm{~Hz}$ in the $F_{2}\left({ }^{1} \mathrm{H}\right)$ dimension and 31443 in the $F_{1}\left({ }^{13} \mathrm{C}\right)$ and with an acquisition time of $0.37 \mathrm{~s}$. The long-range delay was optimized for a coupling constant of $10 \mathrm{~Hz}$. The relaxation delay was $2 \mathrm{~s}$, the data collection matrix was $4048 \times 256$, the $t_{1}$ dimension was zero-filled to $1 \mathrm{k}$ data points and a $\pi / 2$ square sine bell window was applied in both dimensions. ROESY spectra were acquired using a spectral width of $6009 \mathrm{~Hz}$, an acquisition time of $0.17 \mathrm{~s}$, relaxation delay of $2 \mathrm{~s}$, mixing time of $1000 \mathrm{~ms}$, and 24 transients (four dummy scans) for each of the 256 increments. The mixing time was optimized using the t1ir1d pulse program.

The LC-MS system consisted of an Ultimate 3000 series RSLC (Dionex, Germaring, Germany) liquid chromatography and an Orbitrap mass spectrometer (Thermo Fisher Scientific, Bremen, Germany). HPLC was performed using an Acclaim C18 Column 
$(150 \times 2.1 \mathrm{~mm}, 2.2 \mu \mathrm{m}$, Dionex) at a constant flow rate of $300 \mu \mathrm{min}^{-1}$ using a binary solvent system: solvent $\mathrm{A}, \mathrm{H}_{2} \mathrm{O}$ with $0.1 \% \mathrm{HCOOH}$ and solvent $\mathrm{B}, \mathrm{MeCN}$ with $0.1 \% \mathrm{HCOOH}$. The HPLC gradient system started with $2 \% \mathrm{~B}$ and linearly increased to $30 \% \mathrm{~B}$ in $10 \mathrm{~min}$, then increased to $90 \% \mathrm{~B}$ in $14 \mathrm{~min}$, held for $4 \mathrm{~min}$ and brought back to the $2 \% \mathrm{~B}$ initial condition before being held for $5 \mathrm{~min}$ to re-equilibrate the column before the next injection. Full-scan mass spectra were generated using $30,000 \mathrm{~m} / \Delta m$ resolving power, and for $\mathrm{MS}^{2}$ (CID) experiments, the resolution power was set to $7500 \mathrm{~m} / \Delta m$. The mass accuracy was better than $3 \mathrm{ppm}$ for MS and $\mathrm{MS}^{2}$ experiments. Aliquots with concentrations of $40 \mu \mathrm{g} \mathrm{ml}^{-1}$ of metabolites were used for LC/MS analysis.

\subsection{Plant material}

Seeds of $P$. nudicaule L., P. alpinum L. (both garden varieties), $P$. somniferum $\mathrm{L}$. var. nigrum, $P$. somniferum $\mathrm{L}$. var. album, and $P$. californicum A. Gray were obtained from the Leibniz Institute of Plant Genetics and Crop Plant Research (Gatersleben, Germany), germinated and grown in soil in the greenhouse facilities of the Max Planck Institute for Chemical Ecology (Jena, Germany) where voucher specimens are lodged. The temperature was $20-24^{\circ} \mathrm{C}$ during the day and $18-21^{\circ} \mathrm{C}$ during the night. Relative air humidity was between $60 \%$ and $70 \%$. The natural daily photoperiod was supported with $16 \mathrm{~h}$ illumination from Phillips Sun-T Agro $400 \mathrm{Na}$ lights. Fresh petals of $M$. cambrica (L.) Vig. were obtained from the botanical garden of the Friedrich Schiller University Jena, Germany. Lyophilized petals of $P$. atlanticum (Ball) Coss., $P$. pilosum Sibth. and Sm., and P. aculeatum Thunb. were provided by Prof. Kadereit, Institute of Special Botany and Botanical Garden, Johannes Gutenberg University Mainz, Germany.

\subsection{Extraction and sample preparation}

Fresh petals of $P$. nudicaule, $P$. alpinum, $M$. cambrica and other Papaver species and varieties were harvested, lyophilized, ground and extracted with $90 \% \mathrm{MeOH}(3 \times 25 \mathrm{ml})$ in an ultrasonic bath. The combined extracts were partitioned against n-hexane $(3 \times 30 \mathrm{ml})$ and the aqueous phase was used as follows: samples for semipreparative and quantitative analytical HPLC were passed through a PTFE membrane filter $(0.45 \mu \mathrm{m})$ prior to injection. Samples for basic hydrolysis, isolation of nudicaulins I and II from $P$. nudicaule and nudicaulins IX and $\mathbf{X}$ from $M$. cambrica were used as described below.

\subsection{Basic hydrolysis of acylated nudicaulins and isolation of nudicaulins I and II}

The aqueous phase remaining after defatting the petal extracts of $P$. nudicaule was loaded on SPE cartridges (LiChrolut $\mathrm{C}_{18} ; 1 \mathrm{~g}$ ) and eluted with water (fraction $\mathrm{A} 1$ ), $30 \% \mathrm{MeOH}$ (fraction A2), and finally with $\mathrm{MeOH}$ (fraction A3). Fractions $\mathrm{A} 1$ and $\mathrm{A} 3$ were discarded, while the colored fraction $\mathrm{A} 2$ was dried and then reconstituted in phosphate buffer (10 mM, pH 5.6). The solution was loaded onto a strong cation exchange (SCX) SPE cartridge (1 g). The efflux (fraction B1) and the eluate with $\mathrm{MeOH}(6 \mathrm{ml})$ (B2) contained the kaempferol glycosides. The last elution step using a 1:1 (v:v) mixture of conc. aqueous solution of $\mathrm{NH}_{3}$ in $\mathrm{MeOH}(6 \mathrm{ml})$ resulted in fraction B3, which contained nudicaulins I-VIII. For basic hydrolysis, the fraction was evaporated to dryness and reconstituted in $50 \% \mathrm{MeOH}(4 \mathrm{ml})$ in a $5 \mathrm{ml}$ volumetric flask. $\mathrm{NaOH}(1 \mathrm{M}, 600 \mu \mathrm{l})$ was added, filled to a volume of $5 \mathrm{ml}$ by the addition of distilled water, and stirred for $30 \mathrm{~min}$ at room temperature. The progress of hydrolysis was monitored by HPLC (method 2). The hydrolysis was stopped by the addition of glacial acetic acid ( $100 \mu \mathrm{l})$. Nudicaulins I and II were isolated by prep. HPLC (method 1) and fully characterized by NMR and MS. The aqueous phases of defatted petal extracts of $P$. alpinum (containing nudicaulins $\mathbf{I}-\mathbf{V I I I}$ ) and $M$. cambrica (containing nudicaulins I, II, V, VI, IX, and $\mathbf{X}$ ) were treated in the same manner.

\subsection{Identification of nudicaulins, flavonols and anthocyanins}

Nudicaulins IX and $\mathbf{X}$ were isolated from the $M$. cambrica crude extract by prep. HPLC (method 1) and analyzed as a mixture by NMR (Table 2) and MS. Nudicaulins III, IV and $\mathbf{V}$ were isolated from the $P$. nudicaule crude extract by prep. HPLC (method 1) and also analyzed by NMR. Nudicaulins $\mathbf{V}$ and VI were identified in the $P$. nudicaule crude extract by LC-SPE-NMR with LC method 2. The trapped analytes were transferred by capillary to the NMR flow cell as described above and measured in $\mathrm{CD}_{3} \mathrm{CN}$ or $\mathrm{CD}_{3} \mathrm{OD}$. The MS data of nudicaulins were acquired by LCMS analysis of extracts as described above. The identification of flavonols and anthocyanins was based on LCMS analysis.

\subsection{Calibration curve and quantification of nudicaulins}

A stock solution of nudicaulin I ( $5 \mathrm{mg}$ in $20 \%$ aq. $\mathrm{MeOH}$ ) was prepared in a $5 \mathrm{ml}$ volumetric flask. The stock solution was probed for purity by HPLC at different wavelengths $(210,254,280,350$, $460 \mathrm{~nm}$ ), and a purity of $89.2 \%$ was calculated based on the absorption at $210 \mathrm{~nm}$. Five calibration solutions were prepared from the stock solution by dilution with $20 \%$ aq. $\mathrm{MeOH}$ in a $5 \mathrm{ml}$ volumetric flask. Final nudicaulin I concentrations were 0.09, 0.18, 0.23, 0.36 and $0.45 \mathrm{mg} \mathrm{ml}^{-1}$. The calibration solutions were stored in a refrigerator $\left(+4{ }^{\circ} \mathrm{C}\right)$ in tightly closed vials until use. A volume $(10 \mu \mathrm{l})$ of each calibration solution was injected five times and measured by HPLC (method 2). A calibration curve was derived (Fig. S5). Each of the hydrolyzed nudicaulin samples obtained from petals was probed three times by HPLC (method 2) to investigate for the presence of nudicaulins.

\subsection{Analytical data of nudicaulins}

\subsubsection{Nudicaulin $\mathbf{I X}$}

${ }^{1} \mathrm{H}$ NMR and ${ }^{13} \mathrm{C}$ NMR data are shown in Table 2. HRESIMS: $\mathrm{m} / \mathrm{z}$ 1016.30187 ([M+H $]^{+}, \mathrm{C}_{47} \mathrm{H}_{54} \mathrm{NO}_{24}$, calc. 1016.30358). ESIMS/MS:

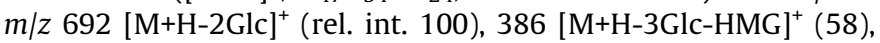
$854[\mathrm{M}+\mathrm{H}-\mathrm{Glc}]^{+}(12)$.

\subsubsection{Nudicaulin $\boldsymbol{X}$}

${ }^{1} \mathrm{H}$ NMR and ${ }^{13} \mathrm{C}$ NMR data are shown in Table 2. HRESIMS: $\mathrm{m} / \mathrm{z}$ $1016.30187\left([\mathrm{M}+\mathrm{H}]^{+}, \mathrm{C}_{47} \mathrm{H}_{54} \mathrm{NO}_{24}\right.$, calc. 1016.30358). ESIMS/MS:

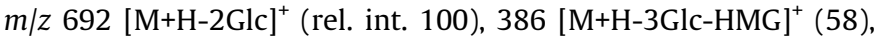
$854[\mathrm{M}+\mathrm{H}-\mathrm{Glc}]^{+}(12)$.

\section{Acknowledgments}

This work was supported by a FP7 Marie Curie Intra European Fellowship from European Union to Dr. E. Tatsis (BIOSYN-NUDICAUL project, Contract Number 221274). The authors are indebted to Prof. J.W. Kadereit for advice concerning suitable Papaver species and for kindly providing petals and Dr. W. Schliemann for fruitful discussions. We are grateful to the Botanical Garden of the Friedrich Schiller University Jena for petals of Meconopsis cambrica. Thanks are given to the MS group of the Max Planck Institute for Chemical Ecology for acquiring mass spectra, the greenhouse team for raising plants, and Emily Wheeler for editorial help in the preparation of this manuscript. 


\section{Appendix A. Supplementary data}

Supplementary data associated with this article can be found, in the online version, at http://dx.doi.org/10.1016/j.phytochem.2013. 04.011.

\section{References}

Carolan, J.C., Hook, I.I., Chase, M.W., Kadereit, J.W., Hodkinson, T.R., 2006. Phylogenetics of Papaver and related genera based on DNA sequences from ITS nuclear ribosomal DNA and plastid trnL intron and trnL-F intergenetic spacers. Ann. Bot. 98, 141-155.

Cornuz, G., Wyler, H., Lauterwein, J., 1981. Pelargonidin 3-malonylsophoroside from the red Iceland poppy Papaver nudicaule. Phytochemistry 20,1461-1462.

Elven, R., Petrovsky, V.V., Solstad, H., 2009. Typification of names in Papaver sect. Meconella Spach (Papaveraceae). Taxon 58, 985-990.

Fabergé, A.C., 1943. The genetics of the Scapiflora section of Papaver. II. The alpine poppy. J. Genet. 45, 139-170.

Finefield, J.M., Sherman, D.H., Kreitman, M., Williams, R.M., 2012. Enantiomeric natural products: occurrence and biogenesis. Angew. Chem. Int. Ed. Engl. 51, 4802-4836.

Goto, T., Kondo, T., 1991. Structure and molecular stacking of anthocyanins - flower color variation. Angew. Chem. Int. Ed. Engl. 30, 17-33.

Grotewold, E., 2006. The genetics and biochemistry of floral pigments. Annu. Rev. Plant Biol. 57, 761-780.

Harborne, J.B., 1965. Plant polyphenols. XV. Flavonols as yellow flower pigments. Phytochemistry 4, 647-657.

Kadereit, J.W., 1997. The genus Papaver L. in the Mediterranean area. Lagascalia 19, 83-92.
Kadereit, J.W., Preston, C.D., Valtuena, F., 2011. Is Welsh poppy, Meconopsis cambrica (L.) Vig. (Papaveraceae), truly a Meconopsis? New J. Bot. 1, 80-88.

Morikawa, T., Wang, L.B., Ninomiya, K., Nakamura, S., Matsuda, H., Muraoka, O., Wu, L.J., Yoshikawa, M., 2009. Medicinal flowers. XXX. Eight new glycosides, everlastosides F-M, from the flowers of Helichrysum arenarium. Chem. Pharm. Bull. 57, 853-859.

Ono, E., Ruike, M., Iwashita, T., Nomoto, K., Fukui, Y., 2010. Co-pigmentation and flavonoid glycosyltransferases in blue Veronica persica flowers. Phytochemistry 71, 726-735.

Price, J.R., Robinson, R., Scott-Moncrieff, R., 1939. The yellow pigment of Papaver nudicaule Part I. J. Chem. Soc., 1465-1468.

Schliemann, W., Schneider, B., Wray, V., Schmidt, J., Nimtz, M., Porzel, A, Böhm, H. 2006. Flavonols and an indole alkaloid skeleton bearing identical acylated glycosidic groups from yellow petals of Papaver nudicaule. Phytochemistry 67 191-201.

Struijs, K., Vincken, J.-P., Verhoef, R., Voragen, A.G.J., Gruppen, H., 2008. Hydroxycinnamic acids are ester-linked directly to glucosyl moieties within the lignan macromolecule from flaxseed hulls. Phytochemistry 69, 1250-1260

Tanaka, M., Fujimori, T., Uchida, I., Yamaguchi, S., Takeda, K., 2001. A malonylated anthocyanin and flavonols in blue Meconopsis flowers. Phytochemistry 56, 373376.

Tanaka, Y., Sasaki, N., Ohmiya, A., 2008. Biosynthesis of plant pigments: anthocyanins, betalains and carotenoids. Plant J. 54, 733-749.

Tatsis, E.C., Schaumlöffel, A., Warskulat, A.C., Massiot, G., Schneider, B., Bringmann, G., 2013. Nudicaulins, yellow flower pigments of Papaver nudicaule: revised constitution and assignment of absolute configuration. Org. Lett. 15, 156-159.

Valtuena, F., Preston, C.D., Kadereit, J.W., 2012. Phylogeography of a tertiary relict plant, Meconopsis cambrica (Papaveraceae), implies the existence of northern refugia for a temperate herb. Mol. Ecol. 21, 1423-1437.

Wind, O., Christensen, S.B., Mølgaard, P., 1998. Colouring agents in yellow and white flowered Papaver radicatum in Northern Greenland. Biochem. Syst. Ecol. 26, 771-779. 